\title{
Prenatal and Perinatal Risk Factors for Autism in China
}

\author{
Xin Zhang $\cdot$ Cong-Chao Lv $\cdot$ Jiang Tian $\cdot$ \\ Ru-Juan Miao • Wei Xi • Irva Hertz-Picciotto • \\ Lihong Qi
}

Published online: 1 April 2010

(C) The Author(s) 2010. This article is published with open access at Springerlink.com

\begin{abstract}
We conducted a case-control study using 190 Han children with and without autism to investigate prenatal and perinatal risk factors for autism in China. Cases were recruited through public special education schools and controls from regular public schools in the same region (Tianjin), with frequency matching on sex and birth year. Unadjusted analyses identified seven prenatal and seven perinatal risk factors significantly associated with autism. In the adjusted analysis, nine risk factors showed significant association with autism: maternal second-hand smoke exposure, maternal chronic or acute medical conditions unrelated to pregnancy, maternal unhappy emotional state, gestational complications, edema, abnormal gestational age ( $<35$ or $>42$ weeks), nuchal cord, gravidity $>1$, and advanced paternal age at delivery ( $>30$ year-old).
\end{abstract}

Keywords Autism $\cdot$ China $\cdot$ Prenatal $\cdot$ Perinatal ·

Risk factors

\section{Introduction}

Autism spectrum disorder (ASD) is a group of neurodevelopmental disorders defined by social and communication

X. Zhang · C.-C. Lv · J. Tian - R.-J. Miao - W. Xi

School of Public Health, Tianjin Medical University, Tianjin 300070, China

I. Hertz-Picciotto

M.I.N.D. Institute and Department of Public Health Sciences, School of Medicine, University of California, Davis, CA 95616, USA

L. Qi (ه)

Department of Public Health Sciences, School of Medicine, University of California, Davis, CA 95616, USA

e-mail: 1hqi@ucdavis.edu deficits and repetitive behaviors that are typically detectable in early childhood, continuing throughout life. Onset of unusual behavior often occurs in infancy or the 2nd year of life and symptoms of autism usually manifest by the age of 3 years. The prevalence of ASD in the general population has been reported to range from two to six per 1,000 (Bertrand et al. 2001; Chakrabarti and Fombonne 2001; Fombonne 1999; Harrison et al. 2006; Williams et al. 2008a; Yeargin-Allsopp et al. 2003). Although there is not an officially reported population-based prevalence of ASD in China available, a study that screened 7,345 children aged 2-6 years old in Tianjin, China, showed that approximately 1.1 individuals in 1,000 had autistic disorder (AD) (Zhang and Ji 2005), lower than those in Staffordshire, England $(1.7 / 1,000)$ (Chakrabarti and Fombonne 2001) Brick Township, America (4/1,000) (Bertrand et al. 2001), Altanta, America (3.4/1,000) (Yeargin-Allsopp et al. 2003), and the South Thames, England (2.5/1,000) (Baird et al. 2006).

The etiology of autism is unclear. ASD is multi-factorial and both genetic and environmental factors contribute to its development. The role of genetics in autism risk is suggested by the higher recurrence rate in siblings of children with autism than in siblings of typically developing children, and the greater concordance rate of monozygotic twins (MZ, 36-96\%) as compared with same-sex dizygotic twins (DZ, 0-30\%; Bailey et al. 1995; Folstein and Rutter 1977; Freitag 2007; Ritvo et al. 1985; Steffenburg et al. 1989). However, the concordance rate for monozygotic twins is less than $100 \%$, indicating that non-genetic factors also must contribute to the causes of autism.

Folstein and Rutter (1977) showed in their UK twin study that autism was associated with some kind of perinatal biological hazard or difference liable to cause brain damage which affected the autistic child and not his co-twin. The twin study conducted by Steffenburg et al. 
(1989) in Denmark, Finland, Iceland, Norway and Sweden reported that the autistic twin had more perinatal stress in 7/10 DZ pairs discordant for AD and only one discordant MZ pair. In general, several studies report that prenatal and perinatal risk factors are associated with autism (Bilder et al. 2009; Brimacombe et al. 2007; Burd et al. 1999; Glasson et al. 2004; Hultman et al. 2002; Juul-Dam et al. 2001; Kinney et al. 2008a, b; Kocijan-Hercigonja et al. 1991; Kolevzon et al. 2007; Larsson et al. 2005; Mason-Brothers et al. 1990; Williams et al. 2008b). Findings include significantly higher incidence of bleeding during pregnancy (Brimacombe et al. 2007; Juul-Dam et al. 2001), breech presentation and low Apgar scores (Larsson et al. 2005), threatened abortion (Hultman et al. 2002), cesarean delivery (Glasson et al. 2004; Hultman et al. 2002) and gestational age at birth $<35$ weeks (Larsson et al. 2005) or $<37$ weeks (Brimacombe et al. 2007; Williams et al. 2008b). Prenatal exposures to thalidomide, rubella, and daily smoking in early pregnancy were also reported to be associated with an increased risk of ASD (Hultman et al. 2002; Rodier et al. 1996; Stromland et al. 1994). Higher risk for autism has been noted with the presence of one or more unfavorable obstetric events (Bolton et al. 1997; Bryson et al. 1988; Deykin and MacMahon 1980; Finegan and Quarrington 1979). Both advanced paternal age (Durkin et al. 2008; Reichenberg et al. 2006; Shelton et al. 2010) and advanced maternal age (Bilder et al. 2009; Durkin et al. 2008; Shelton et al. 2010; Williams et al. 2008b) also have been reported to be associated with increased risk of ASD.

However, the literature is not always consistent in regards to which specific prenatal and perinatal risk factors are associated with autism. To further investigate the relationship between autism and prenatal and perinatal conditions, and to identify factors potentially relevant to the etiology and ultimately, the prevention of this disorder, we conducted a case-control study using children with and without autism in China. Because there is no autism registry in China, the cases in our study were obtained from schools for children with developmental disabilities in Tianjin, and special schools and other organizations providing therapies for school-age children with autism. Most of the school-age children with autism attend schools for children with developmental disabilities and receive special education.

\section{Methods}

\section{Participants}

We conducted a case-control study to investigate prenatal and perinatal risk factors for autism using a cohort of children in China. The research was approved by the IRB at the Tianjin Medical University. Cases came from six Special
Education Schools and two Preschool Autistic Children Special Education Institutions in Tianjin, China. There are six districts in the city of Tianjin, and in each district there is one special education school. A total of 95 autistic children attending these schools or institutions between January and December, 2007, were enrolled, with age ranging from 3 to 21 years old. Every case had a confirmed diagnosis of autism provided by the major hospitals in Tianjin and Beijing, China. Diagnosis information was coded according to the World Health Organization's International Classification of Diseases, Tenth Revision (ICD-10). In addition, after the children entered the study, they were evaluated by pediatric psychologists in Tianjin Children's Hospital using the Childhood Autism Rating Scales (CARS), and all cases were confirmed, with total scores $\geq 30$. The 95 cases were frequency matched to controls on gender and birth year. The controls were typically-developing children aged from 3 to 21 years old who attended a regular preschool, a regular elementary school, a middle school or a high school, all public schools, in Tianjin between January and December, 2007. These schools were randomly selected from the schools in District Hexi, whose socioeconomic level is average and representative of that in Tianjin.

\section{Recruitment and Data Collection}

Risk factors for autism were obtained through selfadministered questionnaires completed by parents with trained study staff present to provide clarifications. All study staff completed rigorous professional training with unified standards before the investigation was initiated. The study staff distributed letters to teachers in the participating schools and institutions, describing the purpose and importance of the study, and the locations for meetings of the participants' parents along with a letter of consent for parents. In special education schools and institutions, teachers delivered this letter to the parents directly, and in regular schools, teachers gave the letter to the students and the students delivered it to their parents. Once letters with written consent had been received, the study staff organized meetings for the participants' parents at different locations to explain the study and questionnaires, instruct the parents how to fill them out, and provide time for them to complete the questionnaires. No data were collected until after written informed consent was received. The selfadministered questionnaires were collected after completion and phone interviews were conducted for missing items to ensure reliability and completeness of the information acquired. For data quality control, $5 \%$ of the study parents were randomly selected and asked to re-complete 150 questions from the questionnaires, and on average, 147 questions per person were answered consistently as before, confirming a $98 \%(147 / 150)$ concordance rate. 


\section{Risk Factors}

We investigated the following potential risk factors for autism.

\section{Parental Characteristics}

Parental characteristics included parental ages at delivery, ethnicity (Han or other minority), occupation, education (college or above), marriage of a close relative, gravidity, exposure to toxins, personality type (introversion, extroversion or neither), history of illnesses and family medical history of dementia, retardation, mental illness, epilepsy, chromosomal disorders, and diabetes. In this paper, we focus on prenatal and perinatal risk factors, and adjust for parental ages at delivery and gravidity; analysis of other parental characteristics such as personality type and education will be reported elsewhere. Binary variables were created to indicate whether parental age is advanced with value 1 if $>30$ years old and 0 otherwise. We chose 30 as the cut point because age level of younger than 30 years old has been used as the reference level in other autism studies (Reichenberg et al. 2006; Tsai and Stewart 1983).

\section{Prenatal Risk Factors}

For prenatal risk factors, we included maternal characteristics and behaviors during pregnancy such as maternal smoking and second-hand cigarette smoke exposure, alcohol consumption, exposure to X-rays, work on computer, use of tocolysis therapy, attempt to terminate pregnancy, contact with toxins, emotional state, disease history and medication history. Maternal disease history during pregnancy included chronic or acute illness (not pregnancy involved): thyroid gland related conditions, epilepsy, mental illness, diabetes, heart disease, hypertension, viral influenza, urticaria, convulsions, serious anaemia, and type-B hepatitis. A summary binary variable was created, with value 1 if any of the above occurred and 0 otherwise. We also considered the following maternal gestational complications: edema, severe hyperemesis, threatened abortion, premature rupture of membrane, serious bleeding before delivery, placenta previa, vaginal infection or bleeding, fever (temperature $>100.4$ degree), and complications caused by malnutrition. A summary binary variable was created with value 1 if any of the above occurred and 0 otherwise.

\section{Risk Factors at Delivery}

We considered the following delivery risk factors: infant gestational age at birth, fetal nuchal cord (umbilical cord wrapped around neck), cesarean delivery, breech birth, and newborn complications: birth weight (in grams), delayed crying and abnormal skin color due to hypoxia, apnoea, aspirated pneumonia, intracranial hemorrhage, sclerederma neonatorum, neonatal jaundice, febrile convulsion, congenital malformations, anoxic encephalopathy, congenital rubella, and gastrointestinal diseases. A summary binary variable was created with value 1 if any of the above occurred and 0 otherwise.

\section{Statistical Analysis}

Simple and multiple logistic regression models were implemented to examine the association between autism and risk factors, and to estimate odds ratios and $95 \%$ confidence intervals (CI), using SAS, version 9.1.3 (SAS Institute, Cary, NC). Initial unadjusted analyses were performed for all potential risk factors to identify those significantly associated with autism. Fisher's exact test was used for factors with frequency $<5$ in either the case or the control group. We considered the overall complications as well as each specific pregnancy complication and newborn complication in analysis when cell sizes were sufficient. For gestational age, preterm $(<35$ weeks) and postterm ( $>42$ weeks) were considered separately as well as combined together as abnormal gestational age $(<35$ or $>42$ weeks). The risk factors with frequency at least 5 in both the case and the control groups were further examined one-by-one using multiple logistic regression models adjusting for advanced paternal age and the two matching variables: gender and birth year. All statistical tests were two sided and $\mathrm{P}<0.05$ was considered statistically significant.

A validation substudy of self-reports was conducted by seeking the medical records on a $10 \%$ randomly selected sample of both cases and controls. We compared the two sources in order to determine the likely magnitude of bias, either due to nondifferential errors or errors differential by case status, i.e., recall bias. When the two sources yielded different values for a given variable, we calculated the Kappa statistic.

\section{Results}

Among the 95 cases and 95 controls, there are 79 males and 16 females in each group, including 23 males and 4 females at age 3-6 years old, 20 males and 5 females 7-10 years old, 19 males and 4 females 11-14 years old, and 17 males and 3 females 15-21 years old. Many factors listed in the methods section had zero occurrence in both case and control groups. Hence we only present the factors with informative results below. 
Unadjusted Analysis

\section{Prenatal Risk Factors}

In the unadjusted analyses, seven maternal conditions during gestation were significantly associated with risk of autism (Table 1); the strongest of these were: frequent maternal second-hand smoke exposure, chronic and acute medical conditions unrelated to pregnancy, maternal unhappy emotional state, and one or more gestational complications (Table 1). The odds ratios of all these risk factors were at least 3 . The frequency of the number of maternal gestational complications is also listed in Table 1 . The frequency of mothers having two or more gestational complications was much higher in the case group than in the control group (26.3\% vs. $3.2 \%)$. On the other hand, the unadjusted analyses did not show significant associations between autism and X-ray exposure, work at a computer, use of tocolysis therapy, viral influenza, and edema (Table 1). Other significant or suggestive associations were observed but the number of exposed controls were small.

\section{Risk Factors at Delivery}

Seven characteristics at the time of delivery were significantly associated with autism in the unadjusted analyses and all these characteristics had an odds ratio of at least 2 except for cesarean delivery: abnormal gestational age including preterm (16.9\% in cases vs. $4.2 \%$ in controls) and postterm ( $8.4 \%$ in cases vs. $4.2 \%$ in controls), nuchal cord (23.2\% in cases vs. $6.3 \%$ in controls), cesarean delivery $(50.0 \%$ in cases vs. $35.8 \%$ in controls), delayed crying ( $11.6 \%$ in cases and $2.1 \%$ in controls), newborn complications $(29.5 \%$ in cases and $4.2 \%$ in controls), apnoea (11.6\% in cases and $1.1 \%$ in controls), and neonatal jaundice (11.6\% in cases and $1.1 \%$ in controls) (Table 1), though several of these were based on small numbers for exposed controls. However, frequency of abnormal birth weight $(<2,500 \mathrm{~g}$, no overweight babies in our sample) was not significantly different between the case and the control groups (Table 1).

\section{Parental Characteristics}

The unadjusted analyses showed that gravidity $>1$ and advanced paternal age at delivery ( $>30$ years old) were significantly associated with autism, but maternal age at delivery older than 30 was not (Table 1).

\section{Adjusted Analyses}

Adjusted analysis was carried out for the factors with frequency at least 5 in both the case and the control groups, including gravidity and the following factors: (a) during pregnancy-maternal second hand smoke exposure, maternal X-ray exposure, maternal work in front of a computer, use of tocolysis therapy, maternal medical conditions (non-pregnancy induced chronic or acute illness), maternal unhappy emotional state, gestational complications, edema, (b) during and after delivery-abnormal gestational age (preterm and postterm were combined to have a sufficient number of events among the controls to allow for an adjusted analysis; however, the biggest difference comparing cases to controls was for preterm deliveries), fetal nuchal cord, cesarean delivery, low birth weight, and advanced maternal age at delivery. After adjusting for gender, birth year, and paternal age at delivery, the factors significant in the univariate analysis remained significant while the insignificant ones remained insignificant except that edema became significant and cesarean delivery became less significant $(\mathrm{p}$ value $=0.06$ ) in the multiple logistic regression model (Table 2). Also, the association with maternal age changed direction, most likely due to the high correlation with paternal age (Pearson Correlation $=0.85$, $\mathrm{p}$ value $<0.0002$ ) .

Thus, the adjusted models showed the following factors to be significantly associated with risk for autism (Table 2): (a) during pregnancy: frequent maternal second-hand smoke exposure $(\mathrm{aOR}=3.53)$, medical conditions (non-pregnancyrelated chronic and acute diseases, $\mathrm{aOR}=4.44$ ), maternal unhappy emotional state $(\mathrm{aOR}=4.08)$, one or more gestational complications ( $\mathrm{aOR}=6.22)$, and edema $(\mathrm{aOR}=2.35)$; (b) at delivery: abnormal gestational age $(\mathrm{aOR}=4.72)$, and fetal nuchal cord $(\mathrm{aOR}=5.41)$; (c) parental characteristics: gravidity ( $>1$ vs. 1$)(\mathrm{aOR}=3.78)$. Advanced paternal age (>30 years) was significant after adjusting for sex and birth year in the multiple logistic model $(\mathrm{aOR}=2.63)$ and remained a significant predictor in all the multiple logistic regression models used to examine the other risk factors, with the adjusted odds ratios ranging from 2.44 to 4.43 .

Adjustment for intermediate variables can introduce bias unless all confounders of associations between outcome (autistic disorder) and both the main exposures and the intermediates have been included (Petersen et al. 2006). We note that additional adjustment for gestational age, a potential intermediate on the causal pathway, does not substantially alter the aORs for almost all the risk factors in Table 2 with the exception of caesarian delivery: the beta coefficient rose $16 \%$, whereby the aOR increased from 1.83 to 2.06 $(95 \% \mathrm{CI}=1.06,3.97)$, after additional adjustment for gestational age. Since it is not clear what proportion of cesarean deliveries occurred after labor began, it is unclear which factor is upstream: gestational age or cesarean delivery.

For the validation substudy comparing self-report with medical records, the $10 \%$ sample included two children 5 years old, two 10 years old, and one each 8, 11, 12, 13, 14 and 17 years old. Variables present in both the medical 
records and questionnaires included maternal X-ray exposure during pregnancy, tocolysis therapy, maternal gestational complications, severe hyperemesis, edema, threatened abortion, gestational age, fetal nuchal cord, caesarian delivery, birth weight, delayed crying, apnoea, neonatal jaundice, gravidity and parental age at delivery. We found $100 \%(10 / 10)$ consistency between the medical records and questionnaires for all variables listed above, in both the case and control groups, except for edema and threatened abortion. For edema and threatened abortion, 90\% (9/10, Kappa

Table 1 Distributions, unadjusted OR and 95\% CI for prenatal/perinatal factors

\begin{tabular}{|c|c|c|c|c|c|c|c|}
\hline & \multicolumn{2}{|c|}{ Case } & \multicolumn{2}{|c|}{ Control } & \multirow[t]{2}{*}{ OR } & \multirow[t]{2}{*}{$95 \% \mathrm{CI}$} & \multirow[t]{2}{*}{$P$} \\
\hline & $\mathrm{N}$ & $\%$ & $\mathrm{~N}$ & $\%$ & & & \\
\hline \multicolumn{8}{|c|}{ Maternal conditions during pregnancy } \\
\hline Second hand smoke exposure & & & & & & & 0.01 \\
\hline None or rarely & 77 & 81.1 & 89 & 93.7 & & & \\
\hline Frequently & 18 & 18.9 & 6 & 6.3 & 3.47 & $1.31,9.18$ & \\
\hline $\mathrm{X}$-ray exposure & & & & & & & 0.27 \\
\hline No & 86 & 90.5 & 81 & 85.3 & & & \\
\hline Yes & 9 & 9.5 & 14 & 14.7 & 0.61 & $0.25,1.48$ & \\
\hline Work before computer & & & & & & & 0.07 \\
\hline No & 77 & 81.1 & 86 & 90.5 & & & \\
\hline Yes & 18 & 18.9 & 9 & 9.5 & 2.23 & $0.95,5.26$ & \\
\hline Tocolysis therapy & & & & & & & 0.29 \\
\hline No & 72 & 75.8 & 78 & 82.1 & & & \\
\hline Yes & 23 & 24.2 & 17 & 17.9 & 1.47 & $0.73,2.96$ & \\
\hline Medical conditions ${ }^{\#}$ & & & & & & & 0.008 \\
\hline No & 76 & 80 & 89 & 93.7 & & & \\
\hline Yes & 19 & 20 & 6 & 6.3 & 3.71 & $1.41,9.76$ & \\
\hline Viral influenza & & & & & & & $0.06^{*}$ \\
\hline No & 83 & 87.4 & 91 & 95.8 & & & \\
\hline Yes & 12 & 12.6 & 4 & 4.2 & 3.29 & $1.02,10.60$ & \\
\hline Unhappy emotional state & & & & & & & 0.0005 \\
\hline No & 66 & 69.5 & 86 & 90.5 & & & \\
\hline Yes & 29 & 30.5 & 9 & 9.5 & 4.20 & $1.86,9.47$ & \\
\hline Gestational complications ${ }^{\&}$ & & & & & & & $<0.0001$ \\
\hline No & 40 & 42.1 & 73 & 76.8 & & & \\
\hline Yes \&\& & 55 & 57.9 & 22 & 23.2 & 4.56 & $2.44,8.54$ & \\
\hline 1 & 30 & 31.6 & 19 & 20.0 & & & \\
\hline 2 & 16 & 16.8 & 1 & 1.1 & & & \\
\hline 3 & 7 & 7.4 & 2 & 2.1 & & & \\
\hline 4 & 2 & 2.1 & 0 & 0 & & & \\
\hline Severe hyperemesis & & & & & & & $0.008 *$ \\
\hline No & 79 & 83.2 & 91 & 95.8 & & & \\
\hline Yes & 16 & 16.8 & 4 & 4.2 & 4.61 & $1.48,14.35$ & \\
\hline Edema & & & & & & & 0.12 \\
\hline No & 75 & 78.9 & 83 & 87.4 & & & \\
\hline Yes & 20 & 21.1 & 12 & 12.6 & 1.84 & $0.85,4.03$ & \\
\hline Threatened abortion & & & & & & & $0.02 *$ \\
\hline No & 84 & 88.4 & 93 & 97.9 & & & \\
\hline Yes & 11 & 11.6 & 2 & 2.1 & 6.09 & $1.31,28.27$ & \\
\hline Premature rupture of membrane & & & & & & & $0.005^{*}$ \\
\hline No & 82 & 86.3 & 93 & 97.9 & & & \\
\hline Yes & 13 & 13.7 & 2 & 2.1 & 7.37 & $1.62,33.64$ & \\
\hline
\end{tabular}


Table 1 continued

$\begin{array}{llllll}\text { Case } & & \text { Control } & \text { OR } & 95 \% \text { CI } & P \\ & \text { N } & \% & \end{array}$

\section{Neonatal characteristics at delivery}

Gestational age

Normal

Abnormal $^{\sim}$

$<35$ weeks

$>42$ weeks

Fetal nuchal cord

No $\quad 73$

Yes

Caesarian delivery+

No

Yes

Birth weight

$2,500-4,500 \mathrm{~g}$

$<2,500$

Delayed Crying

No

Yes

Newborn complications ${ }^{\wedge}$

$\begin{array}{ll}\text { No } & 67 \\ \text { Yes } & 28\end{array}$

Apnoea

No

Yes

Neonatal jaundice

No
Yes

Parental characteristics

Gravidity

1

$>1$

78

82.1

17.9

17

Father's age at delivery

$$
\leq 30
$$

$>30$

56

39

Mother's age at delivery

$$
\leq 30
$$

$>30$

$76 \quad 80$

$19 \quad 20$

$11 \quad 11.6$

70.5

88.4

$\begin{array}{rrr}71 & 74.7 & 8 \\ 24 & 25.3 & \\ 16 & 16.9 & \\ 8 & 8.4 & \end{array}$

87
8
4
4

91.6

8.4

4.2

4.2

4.90

2.45

$1.57,15.32$

$0.71,8.47$

$0.23 *$

0.002

93.7

6.3

4.47

$1.72,11.61$

0.05

64.2

35.8

1.79

$0.99,3.25$

83

87.4

12

12.6

1.73

$0.79,3.80$

$0.02 *$

$\begin{array}{llll}84 & 88.4 & 93 & 97.9\end{array}$

2

2.1

6.09

$1.31,28.26$

$<0.0001 *$

95.8

91

4.2

9.51

$3.18,28.40$

$0.005^{*}$

98.9

94

1.1

12.31

$1.56,97.36$

$0.005^{*}$

98.9

1.1

12.31

$1.56,97.36$

94.7

5.3

3.92

$1.38,11.12$

0.003

78.9

21.1

2.61

$1.38,4.96$

0.15

* Fisher's Exact Test was used to obtain P values when incidence was less than 5

\# Chronic and/or acute illness, not pregnancy induced

\& Gestational complications were defined as in Methods, Prenatal risk factors

\&\& Number of pregnancy complications were listed

$\sim<35$ or $>42$ weeks

+9 subjects with other abnormal mode of delivery were excluded from the analysis

$\wedge$ Newborn complications were defined in Methods, Risk factors at delivery 
Table 2 Adjusted association between autism and risk factors

\begin{tabular}{|c|c|c|c|}
\hline & $\mathrm{aOR}$ & $95 \% \mathrm{CI}$ & $P$ \\
\hline \multicolumn{4}{|l|}{ Maternal conditions during pregnancy } \\
\hline Frequent second-hand smoke exposure & 3.53 & $1.30,9.56$ & 0.01 \\
\hline $\mathrm{X}$-ray exposure & 0.50 & $0.20,1.27$ & 0.15 \\
\hline Work before computer & 2.32 & $0.96,5.62$ & 0.06 \\
\hline Tocolysis therapy & 1.38 & $0.67,2.85$ & 0.39 \\
\hline Medical conditions* & 4.44 & $1.62,12.20$ & 0.004 \\
\hline Unhappy emotional state & 4.08 & $1.77,9.41$ & 0.001 \\
\hline Gestational complications $^{\#}$ & 6.22 & $3.12,12.41$ & $<0.0001$ \\
\hline Edema & 2.35 & $1.04,5.30$ & 0.04 \\
\hline \multicolumn{4}{|l|}{ Neonatal characteristics at delivery } \\
\hline Abnormal gestational age ( $<35$ or $>42$ weeks vs. $35-42)$ & 4.72 & $1.92,11.60$ & 0.0007 \\
\hline Fetal nuchal cord & 5.41 & $1.97,14.81$ & 0.001 \\
\hline Caesarian delivery ${ }^{\&}$ & 1.83 & $0.98,3.43$ & 0.06 \\
\hline Abnormal birth weight $(<2,500 \mathrm{~g}$ vs. $2,500-4,500 \mathrm{~g})$ & 1.46 & $0.65,3.13$ & 0.36 \\
\hline \multicolumn{4}{|l|}{ Parental characteristics } \\
\hline Gravidity (>1 vs. 1 ) & 3.78 & $1.29,11.05$ & 0.02 \\
\hline Father's age at delivery $+(>30$ vs. $\leq 30)$ & 2.63 & $1.38,5.00$ & 0.003 \\
\hline Mother's age at delivery (>30 vs. $\leq 30$ ) & 0.46 & $0.14,1.56$ & 0.21 \\
\hline
\end{tabular}

Results were from multiple logistic regression models predicting autism from, separately, each risk factor, adjusted for paternal age at delivery, gender and birth year

* Chronic and/or acute illness, not pregnancy induced

\# Gestational complications were defined as in Methods, Prenatal risk factors

\& 9 subjects with other abnormal mode of delivery were excluded from the analysis

+ Results were from multiple logistic regression adjusted for sex and birth year

statistics $=0.8$ ) consistency was found in the case group vs. $100 \%$ in the controls.

\section{Discussion}

We have conducted a small but rigorous case-control study, frequency-matched on gender and birth year, to investigate prenatal and perinatal risk factors for autism in China. The main strengths of this investigation include: (a) a comprehensive list of risk factors during gestation and delivery having been examined carefully, (b) self-administered questionnaires completed by parents with trained study staff present to provide clarifications, (c) great efforts in minimizing missing items in the questionnaires to ensure reliability and completeness of the data, and (d) standardized confirmation of cases of autism. The matching procedure by gender and birth year guaranteed similar diagnostic procedures followed by clinicians, and a consistent male-female ratio between cases and controls by birth year. The special education schools and institutions for disabled children are excellent resources for recruiting children with confirmed diagnoses of autism.
We are well aware that although the questionnaire was carefully designed, the information was obtained through retrospective self-report, and therefore differential reporting by cases as compared with controls is possible. To validate the risk factors collected through the questionnaires, we obtained mothers' medical records of obstetric examinations and delivery for a randomly selected sample of 10 autistic children and 10 typically developing children. For over a dozen variables, no errors were found for either the cases or controls. Two variables showed perfect concordance in controls and $90 \%$ in cases. This high rate of concordance confirms the quality of the self-reports, indicating that any bias due to inaccurate or differential recall stemming from the retrospective design would likely be rather small in our study.

We found that maternal unhappy emotional state during pregnancy was significantly associated with autism. Maternal unhappy emotional state refers to mothers feeling unhappy most of the time during pregnancy, usually remembered clearly by mothers regardless of causes. It has been reported that prenatal stress or exposure to environmental or social stressors including family problems is associated with increased autism risk (Kinney et al. 2008a; 
b; O'Donnell et al. 2009; Ward 1990). Previous research in China revealed that more than $44 \%$ of mothers of autistic children experienced emotional nervousness, anxiety, or depression during pregnancy (Xu et al. 2005). Wallace et al. also found maternal depression was associated with higher ADI-R repetitive behavior scores (Wallace et al. 2008). We hypothesize that maternal unhappy mood during pregnancy may increase the level of hormones such as adrenalin in a mother's body, causing placental vasoconstriction which may affect fetal cerebral blood flow, or directly affect fetal hormone levels, with a negative impact on fetal development. Our investigations provide clues for further study in this area.

Maternal second-hand smoke exposure during pregnancy was significantly associated with autism in our study. In China, most people know the harm of cigarette smoking because of governmental education in this area, so Chinese women seldom smoke, especially pregnant women due to the one-child policy. But many Chinese men smoke either privately (e.g. at home) or in public places (public cigarette smoking is not prohibited in China). In our study, maternal second-hand exposure was mostly related to smoking husbands or colleagues in working places. Second-hand smoke includes polycyclic aromatic hydrocarbons, metals, and other chemicals with known adverse health effects, which may cause fetal hypoxia and affect fetal brain development. Although one study showed that maternal smoking during pregnancy was a significant risk factor for autism (Hultman et al. 2002), another did not (Maimburg and Vaeth 2006). Our study had inadequate power to address this hypothesis since maternal smoking was too infrequent in our sample but our finding on second-hand smoke exposure suggests that the compounds in smoke may serve as co-factors with genetic or other environmental hazards.

Previous research identified parity as a potential risk factor for autism, especially the first or the fourth born seemed to have increased risk for autism, although mechanisms underlying this increased risk are unknown (Bilder et al. 2009; Deykin and MacMahon 1980; Lord et al. 1991; Piven et al. 1993). Rates of miscarriage after delivering a child with a developmental disorder are not known, and the impact of caring for a child with developmental disorder on family size goals is unclear. In our study, children with autism did not have siblings due to the one-child policy in China implemented since 1979. However, we found that frequency of children born from second pregnancy, arising after unsuccessful first pregnancy, was significantly higher in the case group than in the control group. Unsuccessful first pregnancy may be related to maternal conditions, environmental exposures, or fetal genetic defects or structural variants. Various factors potentially relevant here include the condition of the uterus, nutritional status, and possibly the interaction between genetic susceptibility and environmental insults.
Our investigation identified gestational complications as a strong risk factor for autism. The occurrence of any type of complication was far higher in the case group (57.9\%) than in the control group (23.2\%). Some of the complications in cases were severe hyperemesis, edema, threatened abortion and premature rupture of membrane. All these specific complications except for edema were significantly associated with risk for autism in the univariate analysis. We could not conduct adjusted analysis for most of the individual complications due to their extremely low event frequency in the control group. For maternal edema we were able to conduct adjusted analysis, and it became a significant risk factor for autism after adjusting for paternal age at delivery, gender and birth year. The finding for edema is consistent with previous findings that generalized maternal edema was associated with the ADI-R social and repetitive behaviors domains (Wallace et al. 2008). Preeclampsia is characterized by new onset of hypertension, proteinuria and generalized edema after 20 weeks of gestation. Hypertension and edema of pregnant women may cause poor placental perfusion and function, and potentially damage fetal development through hypoxia. A recent meta-analysis did not find evidence for an association with autism (Gardener et al. 2009) and a large Swedish study (Hultman et al. 2002) reported a nonsignificant aOR of 1.6 for pre-eclampsia, but their analysis controlled for downstream factors such as gestational age and delivery type, which may have introduced bias and reduced precision. Our study was of insufficient power to evaluate preeclampsia and hypertension, which were rare in both case and control groups.

Our finding that nuchal cord occurred significantly more frequent among children with autism (23.2\%) than among the controls $(6.3 \%)$ has not been previously reported in literature. Nuchal cord may cause fetal deficiency in blood, oxygen and nutrition, which would affect fetal brain development and result in damage to the newborn central nervous system if the inadequate blood flow is severe or lasts long enough.

Our study is consistent with previous findings related to paternal age at delivery. Because maternal and paternal age at delivery are highly correlated, it is virtually impossible in a study this size to adequately control one for the other; only extremely large studies can do so (Shelton et al. 2010). Mixed results are found in numerous previous reports (Bilder et al. 2009; Croen et al. 2007; Cryan et al. 1996; Durkin et al. 2008; Gillberg 1980; Glasson et al. 2004; Maimburg and Vaeth 2006; Reichenberg et al. 2006; Tsai and Stewart 1983; Weiser et al. 2008). Advanced maternal age may increase the chance of chromosomal abnormalities in offspring, and the risk for gestational brain damage in fetus, causing Down Syndrome, dyslexia and mental retardation (Crow 1997; Gillberg 1980). Conflicting 
results across study populations may be partly a consequence of small sample sizes, varying age distributions, and the correlations between maternal and paternal age that make disentangling effects of the two very challenging. In the largest investigation yet of the simultaneous maternal and paternal associations, paternal age was only a risk factor when the mothers were younger than 30 years, suggesting that effect modification combined with low power may also explain earlier inconsistencies (Shelton et al. 2010) and given that most of the mothers in the present sample were young, may explain why we did not see a maternal age association.

Previous studies reported that abnormal gestational age occurs more frequently in births of children who later develop autism. We considered both gestational age $<35$ weeks or $>42$ weeks as abnormal, and found a significant association with risk for autism. Most were preterm: 16 (16.8\%) babies were delivered before 35 gestational weeks in the case group while only 4 (4.2\%) in the control group, supporting reports from Sweden, including that by Larsson et al. 2005, and a large, register-based one by Hultman et al. (Hultman et al. 2002). The latter study also showed that postterm delivery was a risk factor for autism, which, in our study, appeared to be the trend ( 8 postterm deliveries in the case group vs. 4 in the control group), but our sample size and the low frequency of late deliveries precluded a full analysis.

Cesarean delivery showed a borderline association in both the unadjusted and the adjusted analysis $(\mathrm{aOR}=1.83$, $\mathrm{p}$ value $=0.06$ ). An Australian (Glasson et al. 2004) and a Swedish study (Hultman et al. 2002) both reported cesarean sections to be associated with increased autism risk (Brimacombe et al. 2007; Hultman et al. 2002). In the past three decades, the number of births by cesarean delivery has increased sharply in China especially in the eastern region, which covers the major cities of Beijing, Shanghai and Tianjin (Cai et al. 1998). Recent evidence also shows increasing demand for cesarean delivery among young, educated women residing in urban areas (Lei et al. 2003). The causes of cesarean sections in China may be related to fetal status $(38.5 \%)$ such as breech position, umbilical and nuchal cord and placenta function; cephalopelvic factor (28.1\%) primarily cephalopelvic disproportion; maternal medical conditions (18.0\%), e.g., pregnancy-induced hypertension and other illness; and social factors (10.7\%) such that pregnant women or their families choose to have cesarean delivery without clinical indications for cesarean section (Zheng et al. 1996). The prevalence of cesarean delivery in both groups is rather high, but higher in our case group than in the control group (50\% vs. $35.8 \%$ ). However, the above causes of cesarean sections in China suggest that the association with autism may not be a result of the surgical procedure but rather the indications that led to it.
Our study found maternal viral influenza suggestively associated with autism in the unadjusted analysis although it did not reach statistical significance $(\mathrm{p}$ value $=0.06$ ) Maternal infection during pregnancy is a risk factor for schizophrenia and some evidence supports a role in autism (Brown 2006; Brown et al. 2001, 2004; Chess 1977; Deykin and MacMahon 1979; Wilkerson et al. 2002). Animal studies found that prenatal influenza viral infection in pregnant mice yields offspring with behavioral abnormalities reminiscent of autism and schizophrenia (Fatemi et al. 2002; Shi et al. 2003). Research has suggested that prenatal viral infection might dysregulate the fetal immune system and result in viral tolerance in autism (Stubbs and Crawford 1977). Recently, an animal study of influenzainfected pregnant mice showed that deficits in Purkinje cells, a common pathological finding in autism, may be caused by the activation of the maternal immune system (Shi et al. 2009). Some studies (Ashdown et al. 2006; Meyer et al. 2006) suggested that the deleterious consequences of maternal infection on fetal neurodevelopment may be mediated via circulating cytokines induced by the immunogens, rather than the immune agent acting directly on the fetuses. Whether maternal viral influenza during pregnancy damages the regulation of the fetal autoimmune system as an etiologic pathway to autism deserves further investigation.

Neonatal complications including apnoea and jaundice were extremely rare in our control group but much more common in our case group, consistent with the findings of Maimburg et al. that an almost fourfold increased risk for infantile autism was observed in newborns exposed to hyperbilirubinaemia (Maimburg et al. 2008). Neonatal jaundice is caused by accumulated bilirubin (mostly conjugated) physiologically or pathologically; it can, in the pathologic case, damage the central nervous system and result in bilirubin encephalopathy.

In conclusion, our findings support several prenatal and perinatal risk factors for autism. Using 95 children with autism and 95 gender and birth-year matched controls in China, we identified gravidity, maternal unhappy mood during pregnancy, maternal second-hand smoke exposure, maternal chronic or acute illness (non-pregnancy involved), gestational complications, edema, nuchal cord, caesarian delivery, and abnormal gestational age ( $<35$ or $>42$ weeks) to be associated with autism. Some limitations, however, should be noted. Birth history risk factors and related outcomes may be greatly affected by differences in the quality of service provided by hospitals, obstetricians and mother's life style, as can the occurrence of multiple risk factors. The limited sample size prevented us from studying some rare conditions. Nevertheless, many of our findings are consistent with previous reports from the US and Europe, and suggest several prenatal and perinatal environmental factors 
that may adversely affect neurodevelopment through fetal hypoxia, neurotransmitter dysregulation, hormonal, and underlying genetic or chromosomal abnormalities. Future investigations are needed in China using standardized diagnosis criteria, exploring genetics and their interplay with environmental factors, and comparing risk factors in different ethnicities and places, to understand better the etiology of autism.

Acknowledgments The authors thank Dr. Cheryl Walker for her helpful input and all participants for their participation of the study. The study was support by the National Natural Science Foundation of China Grant No. 30771816 (2007.10-2008.12), and the Tianjin Municipal Science and Technology Commission Grant 07JCYBJC 10900 (2007.3-2009.9). This research was supported by Award Number P01ES011269 from the National Institute of Environmental Health Sciences and Award Numbers R833292 and R829388 from the Environmental Protection Agency. The content is solely the responsibility of the investigators and does not necessarily represent the official views of the National Institute of Environmental Health Sciences, the National Institutes of Health or the Environmental Protection Agency.

Open Access This article is distributed under the terms of the Creative Commons Attribution Noncommercial License which permits any noncommercial use, distribution, and reproduction in any medium, provided the original author(s) and source are credited.

\section{References}

Ashdown, H., Dumont, Y., Ng, M., Poole, S., Boksa, P., \& Luheshi, G. N. (2006). The role of cytokines in mediating effects of prenatal infection on the fetus: Implications for schizophrenia. Molecular Psychiatry, 11(1), 47-55.

Bailey, A., Le Couteur, A., Gottesman, I., Bolton, P., Simonoff, E., Yuzda, E., et al. (1995). Autism as a strongly genetic disorder: Evidence from a British twin study. Psychological Medicine, 25(1), 63-77.

Baird, G., Simonoff, E., Pickles, A., Chandler, S., Loucas, T., Meldrum, D., et al. (2006). Prevalence of disorders of the autism spectrum in a population cohort of children in South Thames: The special needs and autism project (SNAP). Lancet, 368(9531), 210-215.

Bertrand, J., Mars, A., Boyle, C., Bove, F., Yeargin-Allsopp, M., \& Decoufle, P. (2001). Prevalence of autism in a United States population: The Brick Township, New Jersey, investigation. Pediatrics, 108(5), 1155-1161.

Bilder, D., Pinborough-Zimmerman, J., Miller, J., \& McMahon, W. (2009). Prenatal, perinatal, and neonatal factors associated with autism spectrum disorders. Pediatrics, 123(5), 1293-1300.

Bolton, P. F., Murphy, M., Macdonald, H., Whitlock, B., Pickles, A., \& Rutter, M. (1997). Obstetric complications in autism: Consequences or causes of the condition? Journal of the American Academy of Child and Adolescent Psychiatry, 36(2), 272-281.

Brimacombe, M., Ming, X., \& Lamendola, M. (2007). Prenatal and birth complications in autism. Maternal and Child Health Journal, 11(1), 73-79.

Brown, A. S. (2006). Prenatal infection as a risk factor for schizophrenia. Schizophrenia Bulletin, 32(2), 200-202.

Brown, A. S., Cohen, P., Harkavy-Friedman, J., Babulas, V., Malaspina, D., Gorman, J. M., et al. (2001). A.E. Bennett research award. Prenatal rubella, premorbid abnormalities, and adult schizophrenia. Biological Psychiatry, 49(6), 473-486.

Brown, A. S., Hooton, J., Schaefer, C. A., Zhang, H., Petkova, E., Babulas, V., et al. (2004). Elevated maternal interleukin-8 levels and risk of schizophrenia in adult offspring. American Journal of Psychiatry, 161(5), 889-895.

Bryson, S. E., Smith, I. M., \& Eastwood, D. (1988). Obstetrical suboptimality in autistic children. Journal of the American Academy of Child and Adolescent Psychiatry, 27(4), 418-422.

Burd, L., Severud, R., Kerbeshian, J., \& Klug, M. G. (1999). Prenatal and perinatal risk factors for autism. Journal of Perinatal Medicine, 27(6), 441-450.

Cai, W. W., Marks, J. S., Chen, C. H., Zhuang, Y. X., Morris, L., \& Harris, J. R. (1998). Increased cesarean section rates and emerging patterns of health insurance in Shanghai, China. American Journal of Public Health, 88(5), 777-780.

Chakrabarti, S., \& Fombonne, E. (2001). Pervasive developmental disorders in preschool children. JAMA, 285(24), 3093-3099.

Chess, S. (1977). Follow-up report on autism in congenital rubella. Journal of Autism and Childhood Schizophrenia, 7(1), 69-81.

Croen, L. A., Najjar, D. V., Fireman, B., \& Grether, J. K. (2007). Maternal and paternal age and risk of autism spectrum disorders. Archives of Pediatrics and Adolescent Medicine, 161(4), 334-340.

Crow, J. F. (1997). The high spontaneous mutation rate: Is it a health risk? Proceedings of the National Academy of Sciences of the United States of America, 94(16), 8380-8386.

Cryan, E., Byrne, M., O’Donovan, A., \& O’Callaghan, E. (1996). A case-control study of obstetric complications and later autistic disorder. Journal of Autism and Developmental Disorders, 26(4), 453-460.

Deykin, E. Y., \& MacMahon, B. (1979). Viral exposure and autism. American Journal of Epidemiology, 109(6), 628-638.

Deykin, E. Y., \& MacMahon, B. (1980). Pregnancy, delivery, and neonatal complications among autistic children. American Journal of Diseases of Children, 134(9), 860-864.

Durkin, M. S., Maenner, M. J., Newschaffer, C. J., Lee, L. C., Cunniff, C. M., Daniels, J. L., et al. (2008). Advanced parental age and the risk of autism spectrum disorder. American Journal of Epidemiology, 168(11), 1268-1276.

Fatemi, S. H., Earle, J., Kanodia, R., Kist, D., Emamian, E. S., Patterson, P. H., et al. (2002). Prenatal viral infection leads to pyramidal cell atrophy and macrocephaly in adulthood: Implications for genesis of autism and schizophrenia. Cellular and Molecular Neurobiology, 22(1), 25-33.

Finegan, J. A., \& Quarrington, B. (1979). Pre-, peri-, and neonatal factors and infantile autism. Journal of Child Psychology and Psychiatry, 20(2), 119-128.

Folstein, S., \& Rutter, M. (1977). Infantile autism: A genetic study of 21 twin pairs. Journal of Child Psychology and Psychiatry, 18(4), 297-321.

Fombonne, E. (1999). The epidemiology of autism: A review. Psychological Medicine, 29(4), 769-786.

Freitag, C. M. (2007). The genetics of autistic disorders and its clinical relevance: A review of the literature. Molecular Psychiatry, 12(1), $2-22$.

Gardener, H., Spiegelman, D., \& Buka, S. L. (2009). Prenatal risk factors for autism: Comprehensive meta-analysis. British Journal of Psychiatry, 195(1), 7-14.

Gillberg, C. (1980). Maternal age and infantile autism. Journal of Autism and Developmental Disorders, 10(3), 293-297.

Glasson, E. J., Bower, C., Petterson, B., de Klerk, N., Chaney, G., \& Hallmayer, J. F. (2004). Perinatal factors and the development of autism: A population study. Archives of General Psychiatry, 61(6), 618-627.

Harrison, M. J., O'Hare, A. E., Campbell, H., Adamson, A., \& McNeillage, J. (2006). Prevalence of autistic spectrum 
disorders in Lothian, Scotland: An estimate using the "capturerecapture" technique. Archives of Disease in Childhood, 91(1), $16-19$.

Hultman, C. M., Sparen, P., \& Cnattingius, S. (2002). Perinatal risk factors for infantile autism. Epidemiology, 13(4), 417-423.

Juul-Dam, N., Townsend, J., \& Courchesne, E. (2001). Prenatal, perinatal, and neonatal factors in autism, pervasive developmental disorder-not otherwise specified, and the general population. Pediatrics, 107(4), E63.

Kinney, D. K., Miller, A. M., Crowley, D. J., Huang, E., \& Gerber, E. (2008a). Autism prevalence following prenatal exposure to hurricanes and tropical storms in Louisiana. Journal of Autism and Developmental Disorders, 38(3), 481-488.

Kinney, D. K., Munir, K. M., Crowley, D. J., \& Miller, A. M. (2008b). Prenatal stress and risk for autism. Neuroscience and Biobehavioral Reviews, 32(8), 1519-1532.

Kocijan-Hercigonja, D., Remeta, D., Orehovac, M., \& Brkljacic, D. (1991). Prenatal, perinatal and neonatal factors in infantile autism. Acta Medica Croatica, 45(4-5), 357-362.

Kolevzon, A., Gross, R., \& Reichenberg, A. (2007). Prenatal and perinatal risk factors for autism: A review and integration of findings. Archives of Pediatrics and Adolescent Medicine, 161(4), 326-333.

Larsson, H. J., Eaton, W. W., Madsen, K. M., Vestergaard, M., Olesen, A. V., Agerbo, E., et al. (2005). Risk factors for autism: Perinatal factors, parental psychiatric history, and socioeconomic status. American Journal of Epidemiology, 161(10), 916-925. discussion 926-918.

Lei, H., Wen, S. W., \& Walker, M. (2003). Determinants of caesarean delivery among women hospitalized for childbirth in a remote population in China. Journal of Obstetrics and Gynaecology Canada, 25(11), 937-943.

Lord, C., Mulloy, C., Wendelboe, M., \& Schopler, E. (1991). Pre- and perinatal factors in high-functioning females and males with autism. Journal of Autism and Developmental Disorders, 21(2), 197-209.

Maimburg, R. D., \& Vaeth, M. (2006). Perinatal risk factors and infantile autism. Acta Psychiatrica Scandinavica, 114(4), 257-264.

Maimburg, R. D., Vaeth, M., Schendel, D. E., Bech, B. H., Olsen, J., \& Thorsen, P. (2008). Neonatal jaundice: A risk factor for infantile autism? Paediatric and Perinatal Epidemiology, 22(6), 562-568.

Mason-Brothers, A., Ritvo, E. R., Pingree, C., Petersen, P. B., Jenson, W. R., McMahon, W. M., et al. (1990). The UCLA-University of Utah epidemiologic survey of autism: Prenatal, perinatal, and postnatal factors. Pediatrics, 86(4), 514-519.

Meyer, U., Feldon, J., Schedlowski, M., \& Yee, B. K. (2006). Immunological stress at the maternal-foetal interface: A link between neurodevelopment and adult psychopathology. Brain, Behavior, and Immunity, 20(4), 378-388.

O’Donnell, K., O'Connor, T. G., \& Glover, V. (2009). Prenatal stress and neurodevelopment of the child: Focus on the HPA axis and role of the placenta. Developmental Neuroscience, 31(4), 285-292.

Petersen, M. L., Sinisi, S. E., \& van der Laan, M. J. (2006). Estimation of direct causal effects. Epidemiology, 17(3), 276-284.

Piven, J., Simon, J., Chase, G. A., Wzorek, M., Landa, R., Gayle, J., et al. (1993). The etiology of autism: Pre-, peri- and neonatal factors. Journal of the American Academy of Child and Adolescent Psychiatry, 32(6), 1256-1263.

Reichenberg, A., Gross, R., Weiser, M., Bresnahan, M., Silverman, J., Harlap, S., et al. (2006). Advancing paternal age and autism. Archives of General Psychiatry, 63(9), 1026-1032.

Ritvo, E. R., Freeman, B. J., Mason-Brothers, A., Mo, A., \& Ritvo, A. M. (1985). Concordance for the syndrome of autism in 40 pairs of afflicted twins. American Journal of Psychiatry, 142(1), 74-77.
Rodier, P. M., Ingram, J. L., Tisdale, B., Nelson, S., \& Romano, J. (1996). Embryological origin for autism: Developmental anomalies of the cranial nerve motor nuclei. The Journal of Comparative Neurology, 370(2), 247-261.

Shelton, J., Tancredi, D., \& Hertz-Picciotto, I. (2010). Independent contributions of advanced maternal and paternal ages for autism risk. Autism Research, 3(1), 30-39.

Shi, L., Fatemi, S. H., Sidwell, R. W., \& Patterson, P. H. (2003). Maternal influenza infection causes marked behavioral and pharmacological changes in the offspring. The Journal of Neuroscience, 23(1), 297-302.

Shi, L., Smith, S. E., Malkova, N., Tse, D., Su, Y., \& Patterson, P. H. (2009). Activation of the maternal immune system alters cerebellar development in the offspring. Brain, Behavior, and Immunity, 23(1), 116-123.

Steffenburg, S., Gillberg, C., Hellgren, L., Andersson, L., Gillberg, I. C., Jakobsson, G., et al. (1989). A twin study of autism in Denmark, Finland, Iceland, Norway and Sweden. Journal of Child Psychology and Psychiatry, 30(3), 405-416.

Stromland, K., Nordin, V., Miller, M., Akerstrom, B., \& Gillberg, C. (1994). Autism in thalidomide embryopathy: A population study. Developmental Medicine and Child Neurology, 36(4), 351-356.

Stubbs, E. G., \& Crawford, M. L. (1977). Depressed lymphocyte responsiveness in autistic children. Journal of Autism and Childhood Schizophrenia, 7(1), 49-55.

Tsai, L. Y., \& Stewart, M. A. (1983). Etiological implication of maternal age and birth order in infantile autism. Journal of Autism and Developmental Disorders, 13(1), 57-65.

Wallace, A. E., Anderson, G. M., \& Dubrow, R. (2008). Obstetric and parental psychiatric variables as potential predictors of autism severity. Journal of Autism and Developmental Disorders, 38(8), $1542-1554$.

Ward, A. J. (1990). A comparison and analysis of the presence of family problems during pregnancy of mothers of "autistic" children and mothers of normal children. Child Psychiatry and Human Development, 20(4), 279-288.

Weiser, M., Reichenberg, A., Werbeloff, N., Kleinhaus, K., Lubin, G., Shmushkevitch, M., et al. (2008). Advanced parental age at birth is associated with poorer social functioning in adolescent males: Shedding light on a core symptom of schizophrenia and autism. Schizophrenia Bulletin, 34(6), 1042-1046.

Wilkerson, D. S., Volpe, A. G., Dean, R. S., \& Titus, J. B. (2002). Perinatal complications as predictors of infantile autism. International Journal of Neuroscience, 112(9), 1085-1098.

Williams, E., Thomas, K., Sidebotham, H., \& Emond, A. (2008a). Prevalence and characteristics of autistic spectrum disorders in the ALSPAC cohort. Developmental Medicine and Child Neurology, 50(9), 672-677.

Williams, K., Helmer, M., Duncan, G. W., Peat, J. K., \& Mellis, C. M. (2008b). Perinatal and maternal risk factors for autism spectrum disorders in New South Wales, Australia. Child: Care, Health and Development, 34(2), 249-256.

Xu, C. Q., Zhang, J. D., \& Zhang, J. (2005). Analysis of risk factors related to children' s autism. Maternal and Child Health Care of China, 20(8), 982-983.

Yeargin-Allsopp, M., Rice, C., Karapurkar, T., Doernberg, N., Boyle, C., \& Murphy, C. (2003). Prevalence of autism in a US metropolitan area. JAMA, 289(1), 49-55.

Zhang, X., \& Ji, C. Y. (2005). Autism and mental retardation of young children in China. Biomedical and Environmental Sciences, 18(5), 334-340.

Zheng, P., Huang, X., \& Wang, S. (1996). The changing trend of cesarean section rates in 35 years. Zhonghua Fu Chan Ke Za Zhi, 31(3), 142-145 